\title{
BMJ Open Prospective audit to evaluate the potential of the coronial system to increase solid organ donation
}

\author{
Huw Twamley, ${ }^{1}$ Andrew Haigh, ${ }^{2}$ Claire Williment, ${ }^{3}$ Cara Hudson, ${ }^{4}$ \\ Julie Whitney, ${ }^{4}$ James Neuberger ${ }^{4}$
}

To cite: Twamley $\mathrm{H}$, Haigh $\mathrm{A}$, Williment $\mathrm{C}$, et al. Prospective audit to evaluate the potential of the coronial system to increase solid organ donation. BMJ Open 2016;6: e010231. doi:10.1136/ bmjopen-2015-010231

- Prepublication history for this paper is available online. To view these files please visit the journal online (http://dx.doi.org/10.1136/ bmjopen-2015-010231).

Received 12 October 2015 Revised 22 December 2015 Accepted 14 January 2016

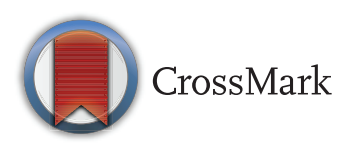

${ }^{1}$ Consultant in Anaesthesia and Critical Care, Royal Preston Hospital, Preston, UK ${ }^{2}$ Coroner's Court, Stafford, UK

${ }^{3} \mathrm{Head}$ of Transplant Development, NHS Blood and Transplant, Bristol,

${ }^{4} \mathrm{NHS}$ Blood and Transplant, Bristol, UK

\section{Correspondence to} Dr James Neuberger; james. neuberger@nhsbt.nhs.uk

\section{ABSTRACT}

Objectives: Anecdotal evidence suggests that organ donation from deceased donors referred to the Coroner/Procurator Fiscal (PF) could be increased if all followed best practice. The aim of this prospective audit was to establish how referrals affected organ donation and to develop evidence-based guidelines to ensure that organ donation can be facilitated safely without interfering in the Coroner/PF's investigative process.

Design: Prospective audit.

Setting: All acute National Health Service Hospitals in the UK where deceased organ donation was considered.

Participants: 1437 deceased patients who met the eligibility criteria for organ donation and were referred to Coroner/PF.

Main outcome measures: Number of cases where permission for transplantation was given, number of organs where permission was refused and number of organs which might have been transplanted if all had followed best practice.

Results: Full permission for organ retrieval was given in $87 \%$ cases and partial permission in $9 \%$. However, if full permission had been given where no autopsy was performed or restrictions seemed unjustified, up to 77 organs (22 lungs, 22 kidneys, 9 pancreases, 9 livers, 8 hearts and 7 small bowels) could have been available for transplant.

Conclusions: Coroners/PFs and their officers show strong support for transplantation but improvement in practice could result in a small but significant increase in life-saving and life-enhancing transplants.

\section{INTRODUCTION}

Solid organ transplantation increases both the quality and length of life of the recipients; ${ }^{2}$ furthermore, renal transplantations save money for the National Health Service (NHS). ${ }^{3}$ Organ donation also provides consolation for the families who supported donation. ${ }^{4}{ }^{5}$ Despite the recent increase in deceased organ donation in the UK, there remains a shortage of donors so up to 1 in 6 people listed for a heart, lung or liver

\section{Strengths and limitations of this study}

- This prospective audit across the UK identifies approaches to improve practice so that more patients can receive the transplant they need and donor families will have the benefits of supporting the wishes of their loved one.

- The study findings were evaluated by a multidisciplinary team including a Coroner.

- Weaknesses include the lack of possible unrecorded information that might have had a significant impact on the decision of the Coroner/ Procurator Fiscal (PF).

- We did not challenge the Coroner/PF asking for an explanation of their decision.

transplant die or become too sick before a graft is available. ${ }^{6}$

Over two-thirds of the solid organs transplanted in the UK are from deceased donors ${ }^{6}$ and one deceased organ and tissue donor could save or improve the lives of up to 11 people (2 kidneys, 1 liver (which could be split for two recipients), 1 heart, 2 lungs, 1 pancreas, 1 small bowel and 2 eyes). The major causes of death associated with deceased donation include intracerebral haemorrhage and trauma. ${ }^{6}$ In many cases referral to the Coroner (or in Scotland, the Procurator Fiscal (PF)) is required. A Coroner/PF's powers to investigate such cases are wide ranging but not limitless. Coroners/PFs are constrained by law to answer four questions: who died; how; when; and, where did the death occur. ${ }^{78}$

Where donation is a possibility, the Coroner/PF has a challenging decision whether to allow organ donation to proceed. If they allow donation, this has the potential to hinder their ability to determine the cause of death, which is their legal obligation. If they veto donation they deny potential recipients the chance of a life-saving or lifeenhancing transplant. Coroners/PFs do not have jurisdiction until someone has died. Therefore, in many cases of potential organ 
donation, they are being asked to make a decision or provide an indication of what their decision may be, before they technically have a remit to do so.

The current policy states that the responsibility for referring deceased patients to the Coroner/PF lies with the attending clinician. The clinician may refer the case to the Coroner/PF themselves or may ask the specialist nurse in organ donation (SNOD) to do this directly. Practice varies between regions and jurisdictions: in some the initial discussion is with the officer and some regions have formal agreements with the Coroner/PF. There is no national agreement whether the Coroner/PF should be approached before or after the family are approached.

In 2013, the four UK health departments, supported by patients, donor families, lay members and clinicians published the UK national strategy 'Taking Organ Transplantation to $2020^{, 9}$ which identified the need to work with Coroners and PFs to maximise the potential for organ donation when referral was required. We therefore conducted a prospective audit, in conjunction with a representative of the Chief Coroner, of all potential organ donors who were referred to the Coroner/PF. The aim was to establish how referrals affected organ donation and to develop evidence-based guidelines to ensure that organ donation can be facilitated safely without interfering in the Coroner/PF's investigative process.

\section{METHODS}

Since 2004, NHS Blood and Transplant (NHSBT) has audited all deaths in NHS hospital intensive care units of those aged 75 years or under dying outside cardiothoracic intensive care units (the Potential Donor Audit) (PDA). ${ }^{10}$ An additional prospective audit was run between 1 September 2014 and 31 March 2015, focusing on the processes for referral to Coroners and actions taken to support the Coroner in reaching a decision. The SNOD were asked to complete a pro forma for all cases that were referred to the Coroner/PF. SNODs were also asked to assess the potential for each organ to be transplanted. The pro forma was developed in house by a small group which included a Coroner, nominated by the Chief Coroner for England (AH), an Intensive Care Consultant (HT), a senior SNOD (JW) and a transplant physician (JN).

There are different legal systems in the UK, with England and Wales acting under the same legislation and has Coroners. Northern Ireland is similar and also has Coroners. Scotland works under different legislation, with slightly different referral criteria terminology and has PF. For the purposes of this paper, the term 'permission' is used which will include 'authorisation' (applicable to Scotland) and 'consent' (applicable to the rest of the UK); 'partial permission' is used when the Coroner/PF allowed donation of some organs. The diagnosis of death in the UK is made according to the criteria determined by the Academy of the Royal Medical Colleges. ${ }^{11}$ Death may be diagnosed by neurological determination (donor after brain death (DBD)) or after circulatory failure (DCD). DCD donation is not legally supported in all countries ${ }^{12} 13$ but these donors account for about one-third of deceased donors.

The results were analysed using SAS Enterprise Guide V.5.1 (SAS Institute, Cary, North Carolina, USA). Nominal logistic regression was used to model the probability of full permission, partial permission or no permission. The reasons for referral were defined by AH. All cases of refusal by Coroner/PF were reviewed by a small group (AH, CW, JW, HT) to assess whether, had permission been given, the organs would have been suitable for transplantation. This decision was made on published contra-indications ${ }^{14}$ and review of existing practice. ${ }^{6}$

\section{RESULTS}

Potential donors: during the time period of the audit, there were 3319 eligible deceased donors identified by the PDA. Referral to the Coroner/PF was reported as required in 1437 (43\%) cases. The Coroners Audit forms were completed for $820(90 \%)$ of the 908 cases where the Coroner/PF was asked for permission to consider organ donation.

\section{Referral to coroner/PF}

The Coroner/PF was not asked for permission for donation in 529 cases. Figure 1 illustrates the reasons for not approaching Coroners/PFs.

The most common reason for referral to a Coroner/PF was sudden and unexpected death $(468(57 \%))$; included in this group were those who died following road vehicle incidents and other accidents. A total of 137 (17\%) were referred for medical reasons, $87(11 \%)$ because of death in suspicious circumstances and in $20(2 \%)$ as a legal requirement. There were $64(8 \%)$ cases referred as the Coroner had asked for this to be performed in all cases of possible organ donation. In $44(5 \%)$, it was not possible to categorise the cause of referral. Autopsies were undertaken in $209(25 \%)$ of the 820 cases.

\section{Response from Coroner/PF}

Full permission was given in the great majority of cases $(\mathrm{n}=693,(85 \%)$; in 57 cases $(7 \%)$, there was a refusal for donation and in $70(9 \%)$ there was permission for donation of some organs. In $77(11 \%)$ of the cases where full permission was given, the Coroner imposed conditions (witness statements (46), pre-retrieval photos (2) and other restrictions (40)). Where partial permission was given, surgery to and retrieval from the chest was excluded in $37(53 \%)$ cases, head and neck in 14 $(20 \%)$, abdomen in $4(6 \%)$, limbs in $2(3 \%)$ and permission for a limited autopsy given in $8(11 \%)$. Other restrictions were made in $18(26 \%)$ cases.

There were 64 cases where referral to Coroner/PF was either as a consequence of the request from the Coroner (47) or where referral was not required (17), permission for donation was given in all (one was for partial donation). 


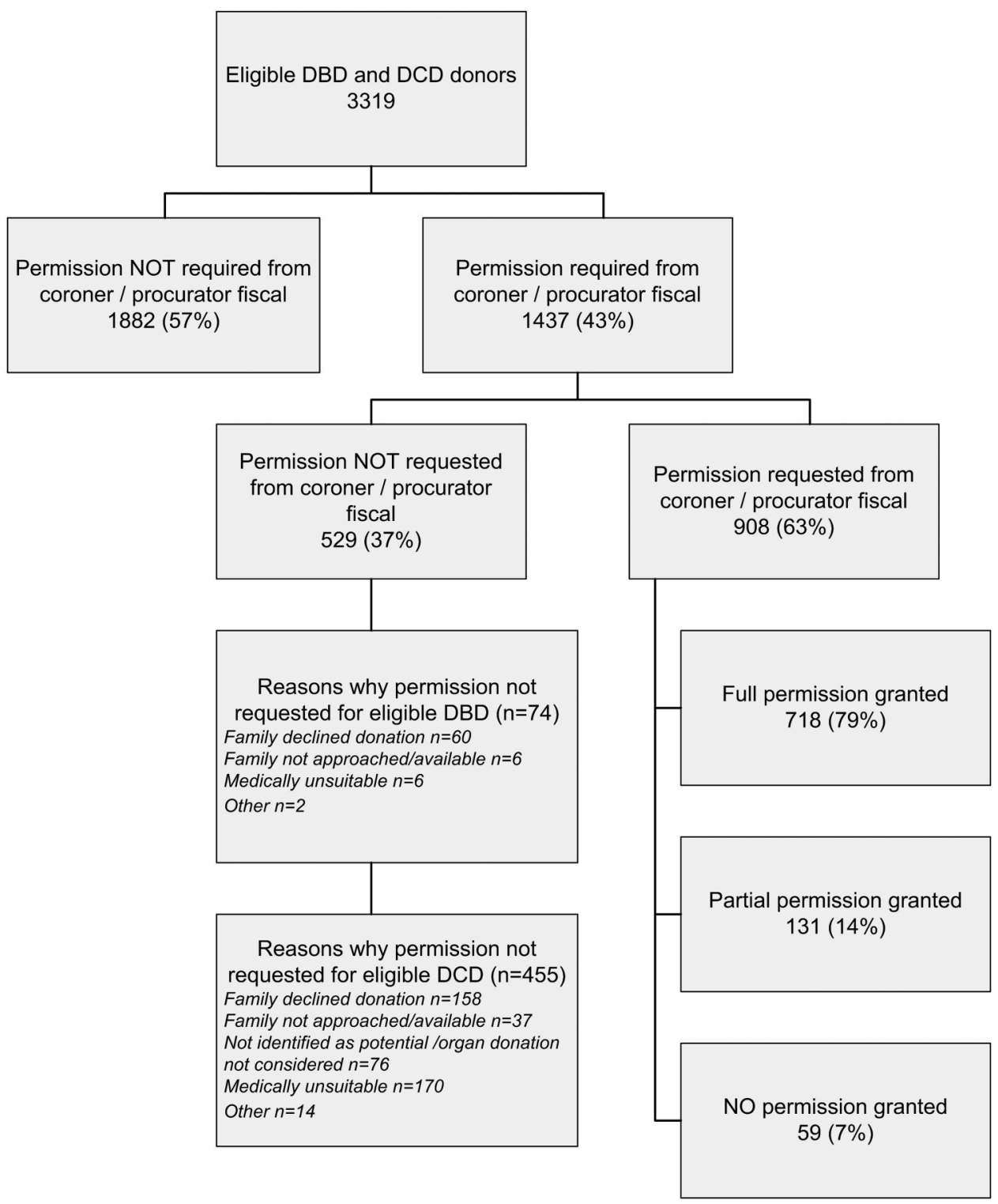

Figure 1 Flow chart of Coroner/PF permission requirement for UK potential donor audit data, 1 September 2014-31 March 2015. DBD, donor after brain death; DCD, donor after circulatory failure.

\section{Factors affecting consent}

During the time period of the audit, 1996 families were approached to seek consent/authorisation for organ donation and the overall family consent/authorisation rate was $58 \%$. If the Coroner/PF had refused permission for organ donation, the family would not be approached.

Table 1 demonstrates Coroner/PF permission level, broken down by timing of family approach for consent/ authorisation for donation to proceed. Coroners gave full permission in $89 \%$ of cases where families had already consented, compared to $77 \%$ in cases where the family were yet to be approached.

\section{Factors associated with Coroner permission}

$\chi^{2}$ Analysis of assessed factors indicated that age, donor type (DBD vs DCD), reason for referral, cause of death, who the organ discussion was held with (Coroner,
Table 1 Coroner permission and effect of family decision where the audit data were completed

\begin{tabular}{|c|c|c|c|c|}
\hline \multirow[t]{2}{*}{$\begin{array}{l}\text { Coroner } \\
\text { permission }\end{array}$} & \multicolumn{2}{|c|}{$\begin{array}{l}\text { Family already } \\
\text { consented/ } \\
\text { authorised }\end{array}$} & \multicolumn{2}{|c|}{$\begin{array}{l}\text { Family not yet } \\
\text { approached }\end{array}$} \\
\hline & $\mathbf{N}$ & Per cent & $\mathbf{N}$ & Per cent \\
\hline Refusal & 21 & 4 & 28 & 11 \\
\hline Partial & 36 & 7 & 32 & 12 \\
\hline Full & 445 & 89 & 201 & 77 \\
\hline Total & 502 & 100 & 261 & 100 \\
\hline
\end{tabular}

Coroner's officer, police, etc), timing of family approach, time between admission and death and whether or not an autopsy was performed were significantly associated with the Coroner permission level. 
In the multivariate (risk-adjusted) nominal logistic regression analysis, the only factors found to be significantly associated with Coroner permission level were the reason for referral, whether or not an autopsy was performed and the cause of death. The results of the multivariate model are shown in table 2. Donor type, who the organ discussion was held with, timing of family approach, time between admission and death were not significant after adjusting for the reason for referral. Donor age was not a significant factor after adjusting for autopsy. The final multivariate model was based on cases where it was known if an autopsy was performed $(\mathrm{n}=703)$. Permission was least likely for patients with a reason for referral of 'Suspicious death', patients who had an autopsy performed and patients with a cardiovascular cause of death. Odds of partial permission were highest for medical reasons for referral, patients who had an autopsy performed and patients with a cardiovascular cause of death.

\section{Potential loss of organs for transplant}

There were 16 cases where the Coroner/PF gave partial or no permission for donation yet no autopsy was performed. There were 45 organs considered to be suitable for transplantation from these 16 cases (lungs 14, kidneys 12, pancreas 6 , liver 5, heart 4, small bowel 4). However, note that in some of these cases the family were not approached as the Coroner/PF had already refused permission, so it is not known whether the family would have consented to/authorised donation.

The audit identified one case of a Coroner/PF changing their mind about permission, from full refusal to full permission, after treatment withdrawal. The patient was on Organ Donor Register, but due to the initial refusal, the family was not approached. This instance led to the potential loss of 8 organs (heart, lungs (2), liver, kidneys (2), pancreas, small bowel).

In one instance, the area where a patient received a fatal injury and the hospital where the patient actually died fell under two different Coroner jurisdictions. The Coroner where the incident occurred was either unable or unwilling to give permission. In organ donation, it is not possible to delay referral until normal working hours and as a result, donation did not proceed, leading to a potential loss of 8 organs (heart, lungs (2), liver, kidneys (2), pancreas, small bowel). In this case, the family had been approached and given consent.

A review of the audit data identified cases where the cause and circumstances of death were very similar (intracranial haemorrhage; suspicious circumstances), but where there was variation in decisions made by Coroners/PFs. Full permission for donation to proceed was given in three cases. In one case, donation was limited to abdominal organs only as the thoracic organs were not clinically suitable for transplantation. In a further three cases, permission was not granted. Sixteen organs from these three eligible donors were reported to be transplantable.

While there are limitations with the case review and no two referrals will ever be identical, this review suggests that there is variation in the decisions that are made regarding organ donation.

\section{DISCUSSION}

\section{Principle findings}

This audit shows there is widespread support from Coroners/PFs and their officers for organ donation and they will often go to great lengths to support organ

Table 2 Results of the multivariate multinomial logistic regression modelling of Coroner permission level

\begin{tabular}{|c|c|c|c|c|c|}
\hline \multirow{2}{*}{$\begin{array}{l}\text { Effect } \\
\text { Reason for referral }\end{array}$} & \multirow[t]{2}{*}{$\begin{array}{l}\text { Coroner } \\
\text { permission level }\end{array}$} & \multirow[t]{2}{*}{$\begin{array}{l}\text { OR for no or } \\
\text { partial permission }\end{array}$} & \multicolumn{2}{|c|}{$\begin{array}{l}95 \% \text { confidence } \\
\text { limits }\end{array}$} & \multirow[t]{2}{*}{ p Value } \\
\hline & & & & & \\
\hline Legal requirement vs general/other & None vs full & 5.27 & 1.24 & 22.38 & 0.0003 \\
\hline Legal requirement vs general/other & Partial vs full & 2.78 & 0.68 & 11.36 & \\
\hline Medical vs general/other & None vs full & 2.83 & 1.19 & 6.73 & \\
\hline Medical vs general/other & Partial vs full & 2.85 & 1.39 & 5.84 & \\
\hline Suspicious vs general/other & None vs full & 5.36 & 2.27 & 12.64 & \\
\hline Suspicious vs general/other & Partial vs full & 1.27 & 0.49 & 3.32 & \\
\hline \multicolumn{6}{|l|}{ Autopsy performed } \\
\hline Yes vs No & None vs full & $29.67^{*}$ & 11.85 & 74.29 & $<0.0001$ \\
\hline Yes vs No & Partial vs full & $34.05^{*}$ & 15.40 & 75.30 & \\
\hline \multicolumn{6}{|l|}{ Cause of death } \\
\hline Cardiovascular vs CNS & None vs full & 3.76 & 1.18 & 11.99 & 0.0006 \\
\hline Cardiovascular vs CNS & Partial vs full & 6.07 & 2.35 & 15.69 & \\
\hline Other vs CNS & None vs full & 1.20 & 0.45 & 3.21 & \\
\hline Other vs CNS & Partial vs full & 0.47 & 0.14 & 1.53 & \\
\hline Trauma vs CNS & None vs full & 0.49 & 0.19 & 1.29 & \\
\hline Trauma vs CNS & Partial vs full & 0.48 & 0.18 & 1.26 & \\
\hline
\end{tabular}

*Note: these ORs should be interpreted with caution due their imprecision.

CNS, central nervous system. 
donation. Nonetheless, this audit over 6 months suggests that at least 77 additional patients might have benefitted from a life-saving transplant. We recognise that this figure should be taken with caution since it was based on the assumptions that the assignment by the team was correct: the likelihood that an organ will be used will depend not only on the risks associated with the organ but also the severity of illness of the potential recipient (a higher risk donor would be appropriate for a sicker recipient). It should be noted that livers can be split and transplanted in to two recipients so the number of potential recipients could be higher if the donation potential was maximised. There is variation between jurisdictions with respect to both full refusals and partial restrictions (ranging from $1.5 \%$ to $12.8 \%$ for full refusal and $0-15.9 \%$ partial refusal (data not shown)). Although much of this will be a consequence of case mix, the audit demonstrated that no particular circumstance or cause of death resulted in an automatic refusal. It is therefore possible for organ donation to occur from the vast majority of patients who require referral to Coroner/PF.

The data also appears to demonstrate that Coroner/ PF permission rates are higher if families have already been approached for a decision regarding organ donation. This could be an illustration of Coroners/PFs adapting their requirements to meet the wishes of the family/deceased to donate (eg,through using witness statements, having a pathologist present at donation, additional forensic photographs). However, there could be some bias in that some of the families may only be approached prior to referral and decision from a Coroner/PF if the SNOD believes that the Coroner/PF is unlikely to object.

The likelihood of refusal is greater if there is a legal requirement to refer to the Coroner/PF, if an autopsy is performed and if there is a cardiovascular cause of death. These factors identify those potential donors where closer and effective interaction between Coroners/PF and the donation and retrieval teams may be more important: the retrieving surgeon will routinely undertake a full laparotomy and thoracotomy before retrieval of abdominal and thoracic organs, respectively, so the presence of a forensic pathologist may allow donation to occur without compromising the role of the Coroner/PF.

\section{Strengths}

This was a prospective study using a tested audit model and completed by SNOD. All cases were reviewed by an expert multidisciplinary team of nurses, managers, physicians and a Coroner. By reviewing not only the decisions but also the pathways, we can agree best practice that will allow organ donation to occur whenever appropriate and without jeopardising the work of the coroners.

\section{Weaknesses}

As with prospective audit, there are some missing data. It is also uncertain whether families would have given consent for organ donation in all cases and whether the organs would have been used for transplantation. It is possible that awareness of the audit would have influenced behaviours so extrapolation to usual practice may give slightly different conclusions. The estimate of potential organ loss is based on information provided to the review team who may have drawn incorrect conclusions.

\section{Meaning of the study and implications for policies}

This study confirms that in the great majority of cases, Coroners/PFs and their officers support deceased organ donation, but there is variation in practice and some apparent inconsistencies that have led to the potential loss of organs for transplantation. Since organ donation leads not only to life-saving and lifeenhancing transplants and saves money for the NHS, but also provides consolation for the bereaved family, every effort should be made to ensure organ donation occurs when appropriate. Key considerations include donation potential, fulfilling the wishes of the donor and the fact of donation and retrieval will not interfere with the judicial process. Coroners/PF and their officers need to be more aware of the benefits of organ donation and balance this against any risk to the judicial process from donation and clinicians need to work more effectively with the Coroners/PFs to ensure that all relevant information is presented in a timely manner before permission is sought and implement any restrictions the Coroner/PF may require. New guidelines will be drawn up between NHSBT and the Coroners/PFs as existing local guidelines appear to have little effect.

\section{Unanswered questions and future research}

The number of autopsies requested by Coroners/PF is falling and fewer have medical qualifications. As society becomes more litigious and risk averse, the pressure on Coroners/PF to refuse permission for organ donation will increase. New ways of working will need to be monitored to ensure that changes do result in more transplants.

Acknowledgements The work of the Specialist Nurses in Organ Donation in completing the audit form is gratefully acknowledged.

Contributors HT helped develop the audit, reviewed the findings and helped write the manuscript. AH helped develop the audit, reviewed the findings and reviewed the manuscript. CW helped develop the audit, ensured completion of the audit forms, reviewed the findings and reviewed the manuscript. $\mathrm{CH}$ helped develop the audit, undertook the statistical analysis and reviewed the manuscript. JW helped develop the audit, ensured support from all Specialist Nurses in Organ Donation, reviewed the findings and reviewed the manuscript. JN helped develop the audit, reviewed the outcomes and helped write the manuscript.

Funding The work received no specific grant from any funding agency but was supported by NHS Blood and Transplant.

Competing interests None declared. 
Ethics approval This audit was approved by the Clinical Audit, Research and Effectiveness Committee of the Organ Donation and Transplantation Directorate of NHS Blood and Transplant.

Provenance and peer review Not commissioned; externally peer reviewed.

Data sharing statement No additional data are available.

Open Access This is an Open Access article distributed in accordance with the Creative Commons Attribution Non Commercial (CC BY-NC 4.0) license, which permits others to distribute, remix, adapt, build upon this work noncommercially, and license their derivative works on different terms, provided the original work is properly cited and the use is non-commercial. See: http:// creativecommons.org/licenses/by-nc/4.0/

\section{REFERENCES}

1. Leppke S, Leighton T, Zaun D, et al. Scientific Registry of Transplant Recipients: collecting, analyzing, and reporting data on transplantation in the United States. Transplant Rev (Orlando) 2013;27:50-6.

2. Wyld M, Morton RL, Hayen A, et al. A systematic review and meta-analysis of utility-based quality of life in chronic kidney disease treatments. PLOS Med 2012;9:e1001307.

3. NICE Clinical Guideline 135. Organ donation for transplantation Costing report. December 2011. http://www.nice.org.uk/guidance/ CG135
4. de Groot J, Vernooij-Dassen M, Hoedemaekers C, et al. Decision-making by relatives about brain death organ donation: an integrative review. Transplantation 2012;93:1196-211.

5. Merchant SJ, Yoshida EM, Lee TK, et al. Exploring the psychological effects of deceased donation on the families of the organ donors. Clin Transplant 2008;22:341-7.

6. Johnson RJ, Bradbury LL, Martin K et al. UK Transplant Registry. Organ donation and transplantation in the UK-the last decade: a report from the UK National Transplant Registry. Transplantation 2014:97(Suppl 1):S1-S27.

7. The Coroners' Society of England and Wales. http://www. coronerssociety.org.uk

8. Crown Office and Procurator Fiscal Service. http://www.copfs.gov.uk

9. Taking Organ Transplantation to 2020. http://www.nhsbt.nhs.uk/ to2020/

10. Barber K, Falvey S, Hamilton C, et al. Potential for organ donation in the United Kingdom: audit of intensive care records. BMJ 2006;332:1124-7.

11. Academy of Medical Royal Colleges. A code of practice for the diagnosis and confirmation of death. http://www.aomrc.org.uk (accessed 17 Dec 2015)

12. Epstein M. Constructing the legal concept of death: the counterharmonic option. Am J Bioeth 2014;14:45-7.

13. Murphy $P G$, Smith $M$. Towards a framework for organ donation in the UK. Br J Anaesth 2012;108(Suppl 1):i56-67.

14. Clinical Contraindications to approaching families for possible organ donation. Pol 188/5.1. http://www.odt.nhs.uk (accessed 17 Dec 2015) 